\title{
NOTAS PARA UN LIBRILLO DE MEMORIA CERVANTINO
}

\author{
Rosa NAVARro DuRÁN \\ Universitat de Barcelona \\ rosanavarro@ub.edu
}

Q uiero ofrecer a Florencio Sevilla Arroyo, mi estimado amigo ausente, unas mínimas notas, unos apuntes a textos que él conocía tan bien: las obras de Miguel de Cervantes; corresponden a lecturas del alcalaíno y podrían figurar en uno de sus librillos de memoria o, si no los necesitó, lo hicieron en la suya.

En la maleta que encuentra don Quijote en Sierra Morena y que registra Sancho hay «un librillo de memoria, ricamente guarnecido» — que luego sabremos que es del Roto o Cardenio-, donde están escritos versos y cartas (Cervantes, 1993: 239). En él, aprovechando su papel en blanco, don Quijote escribirá la carta para Dulcinea y la libranza pollinesca para Sancho.

Y hay también un librillo de memoria en otra maleta o valija, esta vez robada y no hallada: la del francés al que «desvalija» Cortado. Si a ambos unimos el que tiene Dorotea - la de Lope-, como le dice Gerarda a don Bela: «en oyendo un vocablo exquisito, le escribe en un librillo de memoria» (Vega, 1980: 143), vemos que dichos librillos eran de uso corriente, como sanciona su definición en el Diccionario de autoridades: «El librito que se suele traer en la faltriquera, cuyas hojas están embetunadas y en blanco, y en él se incluye una pluma de metal, en cuya punta se ingiere un pedazo agudo de piedra lápiz, con la cual se anota en el librito todo aquello que no se quiere fiar a la fragilidad de la memoria» (Real Academia Española, 1969: II, 400). Quizás Cervantes gozaba de tan buena memoria como su don Quijote, al que le tapian la biblioteca y puede proseguir sus aventuras que imitan las de los libros de caballerías leídos; pero no sería raro que hubiera tenido, como Cardenio o como el francés desvalijado por Cortado, un librito de memoria, donde fuera anotando lo que le llamara la atención en sus muchas lecturas.

No es mi pretensión hablar de ese imaginado librillo de memoria de Miguel de Cervantes, sino ofrecer algunos detalles de sus obras que provienen de lecturas suyas; no son marcadas huellas, sino solo minucias, pero significativas y que nos

Edad de Oro, XL (2021), pp. 373-386, ISSN: 0212-0429 - ISSNe: 2605-3314

DOI: https://doi.org/10.15366/edadoro2021.40.019 
permiten añadir las obras de donde proceden a la biblioteca portátil del alcalaíno, junto a las que el cura y el barbero mencionaron, para lanzarlas al corral y ser pasto del fuego o para salvarlas; en ambos casos su creador las había leído porque sabía de qué hablaba.

\section{Recién SAlidos de LA CURA De La SíFILIS}

Fernán Juárez tradujo la tercera jornada del Ragionamento de Aretino, que salió a la luz con el nombre de Coloquio de las damas en las prensas sevillanas de Juan de León en 1547. Como indica su editora, Gagliardi: «La terza giornata del Ragionamento di Pietro Aretino, dedicata alla vita delle prostitute, fu publicata, clandestinamente, in un'edizione autonoma per la prima volta nel 1534, poi ancora nel 1535 (con due ristampe in due città diverse) en el 1547» (Xuárez y Aretino, 2011: 161).

El traductor cambia el nombre de una de las dos interlocutoras del coloquio; la Nanna de Aretino pasa a ser Lucrecia, que es quien va a contar su vida a su amiga Antonia. Como dice Gagliardi, el traductor, al ver el brusco inicio del diálogo, da un marco histórico al relato y un pasado a las dos damas, y además:

Ignorando le origine romane di Nanna, immaginò nell'Argomento introduttivo che due vecchie amiche d'infanzia bolognesi, dedite per anni al mestieri piú antico del mondo, si ritrovassero nel santuario di Loreto, desiderose di mettersi al corrente delle loro vite. Essendo stata piú avventurosa quella di Lucrecia («como Lucrecia había más peregrinado por el universo»), è lei a dare conto delle sue peripezie in Italia e in Europa [...]. E tuttavia Xuárez non si precluse la possibilità di continuare il dialogo fra le due prostitute, facendo loro promettere, al momento di congedarsi, che si sarebbero incontrate ancora per dare spazio ai racconti di Antonia (Xuárez y Aretino, 2011: XVI).

El «Argumento de la obra», que añade el traductor, comienza: «Lucrecia y Antonia fueron grandes amigas en su mocedad, por ser naturales y haberse criado juntas en la ciudad de Bolonia», y así narra su encuentro:

E habiendo andado Antonia en otras tales ramerías, vinieron a encontrarse, siendo ya ambas mujeres antiguas, en Nuestra Señora de Lorito, y como se conociesen, después de haberse abrazado muchas veces, se sentaron porque Antonia venía muy flaca, que había muy poco que salía de tomar el agua del palo santo (Xuárez y Aretino, 2011: 20, 22).

No hay más que ir al comienzo de El casamiento engañoso de Cervantes para encontrar a otro personaje que sale de una cura de sífilis, como Antonia: 
Salía del Hospital de la Resurrección que está en Valladolid, fuera de la puerta del Campo, un soldado que, por servirle su espada de báculo y por la flaqueza de sus piernas y amarillez de su rostro, mostraba bien claro que, aunque no era el tiempo muy caluroso, debía de haber sudado en veinte días todo el humor que quizá granjeó en una hora (Cervantes, 2016b: 35).

Es el alférez Campuzano y será un amigo suyo, el licenciado Peralta, el que topa con él y se hace cruces ante el aspecto que tiene. Como Campuzano no está «para tener largas pláticas en la calle», Peralta le invita a ir a su posada y allá le contará su casamiento engañoso con una dama — como las del diálogo de Aretino- doña Estefanía de Caicedo, que le había robado todo lo que tenía - aunque las joyas eran falsas - y le dejó en herencia el mal francés.

Pero Cervantes toma de Juárez otra idea: la de que solo una dama cuente su vida, Lucrecia, mientras Antonia apostilla el relato, y al final se abre la continuación con la petición de la narradora a su amiga de que «en el mesmo lugar nos tornemos a ver mañana, porque quería, si dello fueres muy contenta, que me contases alguna partecilla de tus aventuras» (Xuárez y Aretino, 2011: 152), propuesta que acepta Antonia.

Y, como saben los lectores, esa idea es la que organiza su Coloquio de los perros, donde Berganza cuenta su vida a Cipión, y este reserva el relato de la suya para la noche siguiente:

Cipión: Sea esta la manera, Berganza amigo: que esta noche me cuentes tu vida y los trances por donde has venido al punto en que ahora te hallas; y si mañana en la noche estuviésemos con habla, yo te contaré la mía, porque mejor será gastar el tiempo en contar las propias que en procurar saber las ajenas vidas (Cervantes, 2016b: 62).

No son damas, sino perros, pero una y otro prometen, y se queda el final abierto, sin ese segundo coloquio. Esa estructura está tomada de la traducción de Juárez, que es quien añade el comienzo y el final, y Cervantes imita algún detalle más. Así falsamente la estafadora Lucrecia dice: «Mi cama será una carga de paja echada sobre una estera» (Xuárez y Aretino, 2011: 96). ¿Hace falta decir que Cipión y Berganza hablan sobre esteras? Lo precisa el alférez Campuzano: «echados detrás de mi cama en una esteras viejas», y ellos insistirán en que es así (Cervantes, 2016b: 52, 59, 62).

El rufián Monipodio manda sacar «una de las esteras de enea que estaban en el aposento y tenderla en medio del patio», que va a servir de mantel para todo lo que esconde la canasta de colar (Cervantes, 2016a: 63). Y si lo recuerdo es porque precisamente en Rinconete y Cortadillo hay otro eco del Coloquio de las damas. Lucrecia comenta una de sus hazañas a Antonia: «Mira si fue buena, pues que a 
todos los forasteros que venían a mi casa lo contaba, y estuve por mandar hacer coplas sobre ello, si no fuera tenida en el pueblo por mujer vanagloriosa» (Xuárez y Aretino, 2011: 92). En el patio de Monipodio la Gananciosa aconseja a su amiga la Cariharta sobre lo que debe hacer o no hacer con su rufián el Repolido, que acababa de darle una paliza: «Sosiégate, hermana; que antes de mucho le verás venir tan arrepentido como he dicho; y si no viniere, escribirémosle un papel en coplas, que le amargue» (Cervantes, 2016a: 71). Esas «coplas» que, si las escriben podrían amargar al Repolido, son como las que estuvo a punto de mandar hacer Lucrecia sobre una de sus exitosas burlas: coplas satíricas ambas.

\section{MetAMORfosis PERRUnA}

Voy ahora a tomar notas de otro libro que también leyó Cervantes: el Honesto y agradable entretenimiento de damas y galanes de Giovan Francesco Straparola, traducido por Francisco Truchado. La obra original, Le Piacevoli notti, fue publicada en Venecia, por Comin da Trino: en 1550 la primera parte, y en 1553 la segunda. La traducción española de Francisco Truchado se publica en Zaragoza en 1578, por Juan Soler, y la segunda parte se estampa en 1581 en Baeza. Se editarán conjuntamente las dos partes en 1598, en Madrid, por Luis Sánchez; la última edición fue en 1612 en Pamplona por Nicolás de Assiayn ${ }^{1}$; pero Cervantes había leído antes las dos partes de la obra.

Como han visto los estudiosos, la fábula segunda de la noche primera cuenta el robo de un caballo por un ingenioso ladrón que es semejante al del que fue víctima Sancho, como él dice (II, 4): «[...] especialmente yo dormí con tan pesado sueño que quienquiera que fue tuvo lugar de llegar y suspenderme sobre cuatro estacas que puso a los cuatro lados de la albarda, de manera que me dejó a caballo sobre ella y me sacó debajo de mí al rucio sin que yo lo sintiese» (Cervantes, 1993: 584). Más adelante, en el capítulo 27, nos enteramos de que fue Ginés de Pasamonte: «Este Ginés de Pasamonte, a quien don Quijote llamaba Ginesillo de Parapilla, fue el que hurtó a Sancho Panza el rucio» (Cervantes, 1993: 772).

El argumento de la fábula de Straparola, traducido por Truchado, dice: «Casandrino, famosísimo ladrón, le hurta la cama y el caballo con linda astucia al corregidor de Perugia, su amigo, y enmendándose de este vicio se hace hombre de bien» (Straparola, 2016: 113); el procedimiento es el mismo, pero, como bien anota Coppola, disintiendo de Federici (2010), que enlazaba los dos textos (Truchado, 2014: 28-29 y 138, n. ${ }^{\circ}$ 12): «El mismo hurto de caballo refleja el proceder de Brunelo cuando se lo robó Sacripante en el Orlando innamorato de Boiardo

Tomo los datos del estudio introductorio de Leonardo Coppola a su edición (Straparola, 2016: $13,23)$. 
(II, 5, 33-41) y en el Furioso de Ariosto $\left(\mathrm{XXVI}^{2}, 72\right.$ y 74), fuente directa para el robo del asno de Sancho en el Quijote (II, 4)» (Straparola, 2016: 117, n. ${ }^{\circ}$ 67); y cita las palabras del pasaje cervantino que avalan el modelo: «lo mesmo le sucedió a Sacripante cuando, estando en el cerco de Albraca, con esa misma invención le sacó el caballo de entre las piernas aquel famoso ladrón llamado Brunelo» (Cervantes, 1993: 585, e insistió en ello en el capítulo 27). Lo que sucede es que Ginés de Pasamonte no es un mago, sino un ladrón, tan ingenioso que lo veremos en esta segunda parte convertido en un titiritero, en maese Pedro, con su mono sabio y su retablo de Melisendra (Cervantes, 1993: caps. 2, 25 y 26); por tanto, Cervantes imita el pasaje de los poemas épicos, pero lo reduce al ingenio del ladrón porque ha leído la fábula de Straparola, traducida por Truchado, y se ha dado cuenta de la imitación del italiano. Se le superponen las lecturas, y él sabe guisarlas a su modo y conveniencia. La prueba de lo que digo es que hay más recuerdos de los relatos de Straparola en las obras de su lector, Cervantes, y uno de ellos es el que ahora quiero destacar.

En la fábula cuarta de la noche séptima, ya en la Segunda parte del honesto y agradable entretenimiento, nos encontramos con dos perversas hermanas y una malvada suegra que cambiarán los tres bellísimos hijos que da a luz Clareta, la hermosa mujer del rey Archiles — hija de un nigromántico, pero sin bienes de fortuna- por tres perritos:

Partido pues el rey y puesto en largo su viaje, la reina parió tres hijos, dos varones y una hembra, en la misma forma y manera que al rey en su virginal juventud había prometido. La maligna y envidiosa suegra, privada de todo género de piedad y encendida de diabólico y mortal odio, en el momento en que nacieron los hermosos y peregrinos infantes, determinó con dañado e infernal propósito hacer matar los inocentes niños [...]. En este tiempo que la reina parió, parió asimismo una perra dentro de su casa tres perrillos cachorros, dos machos y una hembra, los cuales eran estrellados en la frente y con un collar de diferentes pelos y colores alrededor de los cuellos (Straparola, 2016: 322-323).

Las envidiosas hermanas de Clareta los toman y se los llevan a su suegra para que cambie los preciosos niños recién nacidos por los cachorritos. Así lo hará y se los enseñará a la joven reina: «¿Veis aquí, hija mía, lo que paristes?» (Straparola, 2016: 323).

Y vuelvo al Coloquio de los perros porque hay en él un trueque semejante, aunque en este caso la bruja transforma a los niños en perros. Como le cuenta la Cañizares al perro Berganza — y él se lo narra a su compañero Cipión-, su madre se llamaba Montiela y era, como ella, discípula de la Camacha, brujas las tres. La

2 No es el canto XXVI, sino el XXVII; y en nota Segre y Muñiz recuerdan el pasaje de Boiardo y el de Cervantes (Ariosto, 2002: 1.774-1.775). 
Camacha, envidiosa «porque se le iba subiendo a las barbas en saber tanto como ella, o por otra pendenzuela de celos, que nunca pude averiguar, estando tu madre preñada, y llegándose la hora del parto, fue su comadre la Camacha, la cual recibió en sus manos lo que tu madre parió y mostrole que había parido dos perritos» (Cervantes, 2016b: 117). Y acabará su historia diciendo que, cuando la Camacha se estaba muriendo, «llamó a tu madre y le dijo cómo ella había convertido a sus hijos en perros por cierto enojo que con ella tuvo; pero que no tuviese pena, que ellos volverían a su ser cuando menos lo pensasen» (Cervantes, 2016b: 118). Esa metamorfosis inverosímil es desmentida por el razonable Cipión, aunque admite que el hecho de que ellos, siendo perros, hablen, «es caso portentoso y jamás visto» (Cervantes, 2016b: 129).

Más adelante en el relato de Straparola, los dos niños se convertirán en apuestos mancebos que van en busca de una poma de un árbol encantado, una de las empresas que su hermana Serena les ruega que lleven a cabo. Se encuentran con una maga, Circea, y ella les da un medio para que la feroz serpiente que custodia el jardín en donde está el árbol no les haga daño: «Tomá, pues, esta vestidura toda de espejos cubierta, y uno de vosotros se la ponga y vista, y así vestido se entrará dentro del jardín [...]; le saldrá al encuentro la inhumana bestia y espantable serpiente, y viéndose ella misma en los claros espejos de esa vestidura, cairá encantada en tierra» (Straparola, 2016: 330). No tienen los mismos efectos los espejos del caballero de los Espejos, pero sí le da nombre su sobrevista o casaca «de una tela al parecer de oro finísimo, sembradas por ella muchas lunas pequeñas de resplandecientes espejos» (Cervantes, 1993: 663).

En la fábula segunda de la noche novena de Straparola, Cucurucho, un ingenioso truhan, le pide a un mesonero que haga armar a su mujer con las armas más viejas que estén en la posada. Accederá ella — que se llama Paz-, pero con el peso de las armas, llenas de orín y moho, se caerá al suelo y le será imposible levantarse (Straparola, 2016: 393). Vemos a don Quijote en el suelo tras su primera aventura, la de los mercaderes toledanos, por culpa del tropezón y caída de Rocinante, «y queriéndose levantar, jamás pudo: tal embarazo le causaban la lanza, adarga, espuelas y celada, con el peso de las antiguas armas» (Cervantes, 1993: 69). Él había limpiado las viejas armas «tomadas de orín y llenas de moho» (Cervantes, 1993: 45), pero su peso pudo con él.

La fábula quinta de la noche primera le da a Cervantes la idea del pajar en donde pasar la noche el pícaro estudiante Carraolano del entremés La cueva de Salamanca. No hay más que verle entrar en casa y pedir a Cristina y a su señora Leonarda que le dejen refugiarse de la mala noche que el cielo presagia: «[...] yo no quería ni buscaba otra limosna, sino alguna caballeriza o pajar donde defenderme esta noche de las inclemencias del cielo, que, según se me trasluce, parece que con 
grandísimo rigor a la tierra amenazan» (Cervantes, 1987: 815). Les cuenta que es salmantino, que iba a Roma, pero, muerto su tío, con el que iba, regresa a su tierra desde Francia; que le han robado los compañeros de Roque Guinarde en Cataluña, y que le había tomado la noche en su puerta. Aunque ellas están esperando al barbero Nicolás y al sacristán Reponce en ausencia de Pancracio, el marido de Leonarda y señor de la casa, les da pena el estudiante salmantino. Y como tienen una canasta «llena de mil regalos y de cosas de comer», donde hay «dos capones que aún no están acabados de pelar» (Cervantes, 1987: 814), Cristina le dice a su tía y señora: «Tengámosle en casa esta noche, pues de las sobras del castillo se podrá mantener el real; quiero decir que en las reliquias de la canasta habrá en quien adore su hambre; y más, que me ayudará a pelar la volatería que viene en la cesta» (Cervantes, 1987: 814-816).

En Straparola es el propio marido, Dimitrio, un rico mercader, quien, avisado por su vecino Manucio del comportamiento de su mujer Policena en su ausencia, fingirá ser un miserable pobre, con vestidos de uno de ellos, sucia la cara y manos con lodo y contrahaciendo la voz. Su vecino le aconseja hacerlo así y le dice que llame luego a su puerta:

Demandad, por amor de Dios, que os den posada, aunque sea en el pajar, porque llegáis ahora de camino y con la tempestuosa noche no halláis posada. Por ventura, pues decís que vuestra criada es tan caritativa, se moverá a piedad, y viendo el cruel tiempo os dará en casa donde durmáis; $y$ de esta manera veréis lo que tanto deseáis (Straparola, 2016: 141).

Irá aquella misma noche «con aquella tempestad y fortuna de agua» a llamar a su propia puerta. Cuando la criada se asome a la ventana y pregunte quién llama a esa hora, Dimitrio contesta:

- Señora, yo soy un pobre viejo caminante que por la tempestad de la oscura noche he llegado en esta tierra y no hallo posada ninguna. Por amor de Dios, me deis un pajar o algún poco de lugar en vuestra caballeriza para descansar esta noche.

La moza, movida de piedad, rogó a su ama que por amor de Dios albergara un pobre viejo, porque hacía gran tempestad y no tenía el cuitado donde acogerse para que se enjugase (Straparola, 2016: 141).

Y Policena accederá diciéndole: «Ábrele porque te ayude a asar esas gallinas y perdices» (Straparola, 2016: 141).

Son tres los elementos que trazan el puente entre los dos textos y que señalan claramente la lectura de Cervantes: la mala noche, el refugio en el pajar (o en la caballeriza, como piden ambos), y la volatería que tiene el recién llegado que ayudar a preparar. 


\section{FALDAS SALVADORAS}

Voy ahora al texto de Gli Ecatommiti de Giraldi Cinthio (1565) o de su traducción parcial al español por Luis Gaytán de Vozmediano, Primera parte de las cien novelas de Giraldo Cinthio (1590), que los estudiosos ya han señalado como fuente de pasajes de Los trabajos de Persiles y Sigismunda. Ruffinatto (2012) ha analizado la deuda del pasaje del polaco Ortel Banedre de la novela de Cervantes (Cervantes, 2002: 489-503) con la sexta novelle de la Deca sexta de los Ecatommiti, y Muñoz Sánchez (2019), la de la primera parte del episodio de las dobles bodas de los pescadores (Cervantes, 2002: 341-351) con la novela octava de la segunda década de la obra de Cinthio. Como esta novela sí fue traducida por Gaytán, con razón Muñoz Sánchez no puede dilucidar si se inspiró Cervantes en el original o en la traducción, o en los dos a la vez.

Mis apuntes cervantinos los tomo de esa traducción, ahora editada por Aldomà (2019). Uno es tan ligero que no llega ni a nota: es la condición de Proteo que recomienda Poncio en el ejemplo III con las cortesanas: «sepa mostrarse con ellas un Proteo antes que a costa suya prueben ser Circes o Medusas» (Gaytán, 2019: 112). Lo será uno de los grandes personajes de las comedias de Cervantes: Pedro de Urdemalas, como él mismo dice: «un Proteo fui segundo. / ¡Válgame Dios, qué de trajes / he mudado, y qué de oficios, / qué de varios ejercicios, / qué de exquisitos lenguajes!» (Cervantes, 1998: 235). Tampoco puedo tender un puente directo entre las dos obras con el cambiazo del anillo con diamante por otro falso que le da Vico a la Griega, una cortesana, en el ejemplo II de Cinthio: «Fue la Griega a sacar el dinero, y Vico, entre tanto, guardando aquel fino, sacó deliberadamente un anillo que dalle con el diamante falso, tan semejante al otro que solo un lapidario o platero le conociera» (Gaytán, 2019: 110). Para ver otro parecido tenemos que ir al Entremés del vizcaíno fingido porque Solórzano, apoyado por Quiñones, le cambia una cadena valiosa por otra falsa a doña Brígida, también una cortesana, y consigue dinero y cena, porque como dice la copla que cantan los músicos, «La mujer más avisada / o sabe poco o no nada» (Cervantes, 1987: 797). Es precisamente la condición de «dama» de la engañada la que une ambos cambiazos.

Y hay otro engaño en el mismo ejemplo II: la prueba falsa de un inexistente hurto; y en este caso la víctima será el propio Vico antes de aprender a burlar a las cortesanas. El joven se enamora locamente de una cortesana, la Eslavona, y ella, gracias a una vieja criada suya, logrará que acabe en la cárcel, y después, que lo acusen de haber robado un fardo de rica tela de Holanda a un mercader vecino suyo, cuando la ladrona era ella; el modo es que la vieja «le arrojase algunos pedazos de la holanda que las dos hurtaron», por una ventana baja con reja y siempre abierta, al pobre aposento alquilado que él tenía; Vico no puede entender cómo 
el alguacil ha encontrado en tal lugar la prueba del robo que él no había hecho (Gaytán, 2019: 103-104). La prueba amañada de un inexistente robo la encontramos en La gitanilla, porque Juana Carducha, hija de la dueña del mesón donde se alojan Preciosa, Clemente y Andrés, enamorada de este último, al ver que no tiene esperanza alguna de su amor y que el joven se iba, «puso entre las alhajas de Andrés, que ella conoció por suyas, unos ricos corales y dos patenas de plata, con otros brincos suyos» (Cervantes, 2015: 114); viene luego la denuncia, el asombro del joven y el castigo.

Pero es cierto que uno y otro motivo, el cambiazo y la prueba falseada, no son exclusivos de ambos relatos; mucho más insólito es, en cambio, el puente que traza entre ellos una falda que actúa como salvavidas. En la novela VIII de la segunda década, Ginebra y Lisca están a punto de morir ahogadas; las salvará Posidonio, pero hasta que pueda llegar a ellas nadando, «quedáronsele a la una y a la otra las faldas sobre el agua, a manera de un pabellón, y así juntas como cayeron se sostenían en ella como si fueran dos sirenas» (Gaytán, 2019: 297).

Vamos ahora a Los trabajos de Persiles y Sigismunda, los peregrinos están en una ciudad de Francia, es mediodía, «entraba el calor, y la sombra de una gran torre de la casa les convidó que allí esperasen a pasar la siesta» (Cervantes, 2002: 573); Bartolomé tiende un tapete, se sientan todos a la redonda y van a empezar a comer cuando él, alzando los ojos, dijo a grandes voces: «iApartaos, señores, que no sé quién baja volando del cielo, y no será bien que os coja debajo!» (Cervantes, 2002: 573). Y, en efecto, ven bajar por el aire una figura, que enseguida llega a sus pies:

La cual figura era de una mujer hermosísima que, habiendo sido arrojada desde lo alto de la torre, sirviéndole de campana y de alas sus mismos vestidos, la puso de pies y en el suelo sin daño alguno: cosa posible, sin ser milagro. Dejola el suceso atónita y espantada, como lo quedaron los que volar la habían visto (Cervantes, 2002: 573).

No va a tener la misma suerte Periandro y, arrojado por la misma torre, «como no tuvo vestidos anchos que le sustentasen, hizo el golpe su efecto y dejole casi sin vida» (Cervantes, 2002: 574).

Como Cervantes había leído muy bien a Cinthio, no es raro que las faldas salvadoras de Ginebra y Lisca le inspiraran esa variante aérea como paracaídas.

\section{UNA ATREVIDA Y CURIOSA MUCHACHA, Y EL INESPERADO ROSTRO QUE ESCONDE UN YELMO}

Las Noches de invierno de Antonio Eslava se imprimen en Pamplona, por Carlos de Labayen, en 1609, y son testimonio de que Cervantes seguía leyendo atentamente lo que se publicaba, porque podemos encontrar en la obra dos apuntes de pasajes de la segunda parte de Don Quijote de la Mancha. 
En el libro primero Fabricio le va a contar a su amigo Leonardo la historia de la pérdida del navío de su vecino Albanio; y al comienzo tiene un papel determinante la curiosidad de una hermosa muchacha de dieciséis años, Dorida, enamorada de Fileno, «igual con ella en nobleza y hacienda» (Eslava, 2013: 63), que vive en Candía. Toma puerto en la ciudad un bajel turco destrozado por la tormenta que va cargado «de salvajes indios y gente del todo negra y por aquellas partes jamás vista» (Eslava, 2013: 65).

Pues como acudiese casi toda la más parte de la ciudad a ver gente tan remota y extraña, Dorida, aficionada, como mujer, de novedades, ordenó con su muy amado Fileno que, después que la noturna diosa tendiese su negro manto y sus viejos padres fuesen acostados, fuese disfrazada a la marina con él, y entrasen en un batel a ver el roto navío y la gente tan extraña que en él venía (traza al fin de mozos, donde pocas veces advierten lo que más importa, que siempre se juzgan otras cosas por lo que son y no por lo que pueden ser) (Eslava, 2013: 65).

Hay que acompañar de noche al gobernador Sancho Panza de ronda por su ínsula para encontrar a una muchacha con curiosidad semejante, aunque el objeto de ella sea otro. Dos corchetes llevan ante el señor gobernador a una mujer vestida de hombre, y al acercarle a la cara unas linternas descubren el «rostro de una mujer, al parecer de diez y seis o pocos más años, recogidos los cabellos con una redecilla de oro y seda verde, hermosa como mil perlas» (Cervantes, 1993: 929). Ella contará su historia -es hija de un hidalgo principal y rico-, la razón de su disfraz y su presencia en la calle a tales horas. Su padre la ha tenido encerrada en casa desde que murió su madre, hacía ya diez años, y por ello le entraron ganas de ver mundo o al menos el pueblo donde vive. Como dice:

Cuando oía decir que corrían toros y jugaban cañas y se representaban comedias, preguntaba a mi hermano, que es un año menor que yo, que me dijese qué cosas eran aquellas y otras muchas que yo no he visto; él me lo declaraba por los mejores modos que sabía, pero todo era encenderme más el deseo de verlo [...]. No es otra mi desgracia, ni mi infortunio es otro, sino que yo rogué a mi hermano que me vistiese en hábitos de hombre con uno de sus vestidos y que me sacase una noche a ver todo el pueblo cuando nuestro padre durmiese (Cervantes, 1993: 932).

Él, vestido de mujer, al ver la ronda correrá más que ella, y la curiosa doncella acabará prendida por los corchetes y delante del gobernador. Todo terminará bien y sin más daño que el susto, cosa que no comparte con la complicada historia que se inicia con la salida nocturna de la curiosa muchacha que le dio la idea a Cervantes. 
Y hay aún otro mínimo detalle en la segunda parte del Quijote que muestra la lectura del alcalaíno de las Noches de invierno, cuya impresión es tan cercana a la escritura del texto: la sorpresa al desenlazar el yelmo del caballero vencido.

Es la noche segunda y diálogo tercero «entre Leonardo, Silvio y Albanio, en casa de Fabricio», donde el primero cuenta «los amores de Angélica la Bella» (Eslava, 2013: 137). Dos caballeros se enfrentan para dirimir la cuestión de la honra en entredicho de la hermosa dama, pero nadie sabe quiénes son. Como comenta Leonardo: «¿Quién imaginara que era Mauricio, el hijo mayor del duque, pues iba contra la voluntad de su padre? ¿Y quién pensara que el mantenedor era Gaulo Casio, su hermano tan amado, pues nunca se mostró apasionado en este caso?» (Eslava, 2013: 146). Mauricio vence y mata al mantenedor, y su victoria es recibida con alegría por Angélica y toda la ciudad. Sigue narrando Leonardo:

Pues como Mauricio viese muerto a su contrario, se apeó con mucha ligereza a cortarle la robusta cabeza y presentalla a la alegre Angélica, y como le hubo desenlazado el yelmo, vio que era su más que amado y querido hermano Gaulo Casio el muerto; y admirado o casi espantado de tal tragedia y lastimoso hecho, dejando de efectuar su comenzado intento, lleno de melancolía acompañada de ardientes suspiros, se salió de Ferrara casi desesperado (Eslava, 2013: 146).

No tenemos más que ir a otra victoria, la de don Quijote sobre el caballero de los Espejos y al mismo momento tras ella. La recordamos:

Don Quijote, que no miraba en estos inconvenientes, a salvamano y sin peligro alguno encontró al de los Espejos con tanta fuerza que mal de su grado le hizo venir al suelo por las ancas del caballo, dando tal caída que, sin mover pie ni mano, dio señales de que estaba muerto (Cervantes, 1993: 665-666).

Don Quijote se apea de Rocinante y va sobre el de los Espejos,

y quitándole las lazadas del yelmo para ver si era muerto y para que le diese el aire si acaso estaba vivo, y vio... ¿Quién podrá decir lo que vio sin causar admiración, maravilla y espanto a los que lo oyeren? Vio, dice la historia, el rostro mesmo, la misma figura, el mesmo aspecto, la misma fisonomía, la mesma efigie, la perspectiva mesma del bachiller Sansón Carrasco (Cervantes, 1993: 666).

La admiración de don Quijote se junta a la de Sancho, al que llama para que compruebe lo que pueden los encantadores: «Llegó Sancho, y como vio el rostro del bachiller Carrasco, comenzó a hacerse mil cruces y a santiguarse otras tantas» (Cervantes, 1993: 666).

Solo es la sorpresa absoluta al deslazar el yelmo y descubrir la identidad del caballero vencido lo que une ambos textos: una mínima nota que permite admirar 
cómo fructifica espléndidamente en la imaginación de Cervantes el ligerísimo estímulo de una lectura.

Hay otro pasaje de las Noches de invierno que también le inspiró, y esta vez no para detalles de la segunda parte sino para una de sus Novelas ejemplares, y con ello tenemos una fecha post quem para su escritura. El rey Clodomiro de Macedonia es cautivado por unos moros corsarios, que lo llevan al mismo lugar donde está preso el príncipe Sulpicio, hijo del rey Tolomeo de Polonia; y el joven lo consuela y le dice la traza que ha inventado para lograr la libertad de los dos.

Has de saber, rey y señor mío, que después que fui cautivo y puesto al servicio de Muley, rey de esta provincia, soy muy amado de Brazaida, su hija; y della mil veces he sido persuadido la lleve a mi tierra, y yo la entretengo hasta hallar urgente ocasión con fingidos amores y cautelosas razones, y por este respecto tengo tanta libertad en palacio y se hace todo lo que yo mando. Dígolo esto porque yo procuraré de fletar navío para que con mucho secreto nos vamos a nuestros reinos y salgamos de esta mísera esclavitud; que Brazaida (engañada la quiero llevar conmigo) mandará en el puerto se haga lo que yo dijere (Eslava, 2013: 167).

El favor que Sulpicio ha conseguido de Brazaida nos lleva al que lograrán Ricardo y Leonisa de sus amos, el cadí y su esposa Halima, aunque ellos serán a la vez supuestos intermediarios de sus amores para lograr escapar en un bajel. Estamos en el terreno novelesco de El amante liberal, y la sucesión de peripecias es distinta y mucho más compleja; pero es semejante la reunión de los dos personajes como cautivos por caminos distintos en el mismo lugar, y el cebo del amor como senda para la libertad. Si la huella de lectura de una escena del relato morisco Ozmín y Daraja, de la primera parte del Guzmán de Alfarache, me llevó a situar el término a quo en 1600 para esta novela ejemplar (Cervantes, 2016a: 25), ahora puedo llevarlo más adelante: hasta 1609, la fecha de impresión de las Noches de invierno.

Estas pequeñas notas que he reunido en un librillo de memoria imaginario pretenden solo ser un homenaje a Miguel de Cervantes, que supo libar tan bien algunas flores de los numerosos libros de su biblioteca portátil, y al mismo tiempo ofrecérselo a su gran estudioso, Florencio Sevilla Arroyo. 
BiBLIOGRAFÍA

Ariosto, Ludovico (2002 [1549]). Orlando furioso. Jerónimo de Urrea (trad.). Cesare Segre y M. ${ }^{a}$ de las Nieves Muñiz (eds.). Madrid: Cátedra.

Cervantes, Miguel de (1987). Teatro completo. Florencio Sevilla Arroyo y Antonio Rey Hazas (eds.). Barcelona: Planeta.

Cervantes, Miguel de (1993). El ingenioso hidalgo don Quijote de la Mancha. Florencio Sevilla Arroyo y Antonio Rey Hazas (eds.). Alcalá de Henares: Centro de Estudios Cervantinos.

Cervantes, Miguel de (1998). La entretenida. Pedro de Urdemalas. Florencio Sevilla Arroyo y Antonio Rey Hazas (eds.). Madrid: Alianza Editorial.

Cervantes, Miguel de (2002). Los trabajos de Persiles y Sigismunda. Carlos Romero Muñoz (ed.). Madrid: Cátedra.

Cervantes, Miguel de (2015). La gitanilla. Las dos doncellas. Rosa Navarro Durán (ed.). Madrid: Alianza editorial.

Cervantes, Miguel de (2016a). Rinconete y Cortadillo. El amante liberal. Rosa Navarro Durán (ed.). Madrid: Alianza Editorial.

Cervantes, Miguel de (2016b). El casamiento engañoso. Coloquio de los perros. Rosa Navarro Durán (ed.). Madrid: Alianza Editorial.

EsLAVA, Antonio de (2013 [1609]). Noches de invierno. Julia Barella (ed.). Madrid / Frankfurt am Main: Iberoamericana / Vervuert.

Federici, Marco (2010). «Cervantes lettore di fiabe? Il furto dell'asino nella Sierra Morena». Rivista di Filologia e Letterature Ispanische, 13, pp. 67-75.

Gaytán de Vozmediano, Luis (2019 [1590]). Primera parte de las cien novelas de Giraldo Cinthio. Mireia Aldomà (ed.). Barcelona: Universo de Letras.

MuÑoz SÁnchez, Juan Ramón (2019). «Cervantes, lector de Giraldi Cinzio y Gaitán de Vozmediano: de Gli Ecatommiti y la Primera parte de las cien novelas a Los trabajos de Persiles y Sigismunda». Anales Cervantinos, 51, pp. 197-229.

Real Academia Española (1969). Diccionario de autoridades. Edición facsímil. Madrid: Gredos.

RufFinatTo, Aldo (2012). «Cervantes frente a Cinthio: un curioso juego triangular». Anales Cervantinos, 44, pp. 11-36.

Straparola, Giovan Francesco (2016). Honesto y agradable entretenimiento de damas y galanes. Francisco Truchado (trad.) y Leonardo Coppola (ed.). Madrid: Sial.

Truchado, Francisco (2014). Honesto y agradable entretenimiento de damas y galanes. Marco Federici (ed.). Roma: Nuova Cultura.

VeGA, Lope de (1980 [1632]). La Dorotea. Edwin S. Morby (ed.). Madrid: Castalia.

Xuárez, Fernán y Pietro Aretino (2011 [1547]). Coloquio de las damas. Donatella Gagliardi (ed.). Roma: Salerno Editrice. 


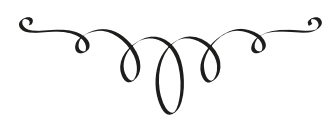

NOTAS PARA UN LIBRILLO DE MEMORIA CERVANTINO

Resumen: El Coloquio de las damas (traducción de Fernán Juárez de la 3. a jornada del Ragionamento de Aretino, 1547), el Honesto y agradable entretenimiento de damas y galanes de Giovan Francesco Straparola, traducido por Francisco Truchado (1. ${ }^{\mathrm{a}}$ parte 1578, 2. $\left.{ }^{a} 1581\right)$, la Primera parte de las cien novelas de Giraldo Cinthio, traducida por Luis Gaytán de Vozmediano (1590) y las Noches de invierno de Antonio Eslava (1609) ofrecen motivos literarios, mínimos detalles, que son pruebas de la lectura de esas obras por Miguel de Cervantes porque él les dio nueva vida en las suyas. Están reunidos en este librillo de memoria imaginario junto a la recreación cervantina.

Palabras Clave: Miguel de Cervantes, motivos literarios, novelas italianas, novelística española, huellas de lectura, recreaciones.

\section{Notes FOR A CERVANTINE MEMOIR}

Abstract: The Coloquio de las damas (Fernán Juárez's translation of the third day of Aretino's Ragionamento in 1547), Giovan Francesco Straparola's Honesto y agradable entretenimiento de damas y galanes translated by Francisco Truchado (first part in 1578, second part in 1581), Girardo Cinthio's Primera parte de las cien novelas translated by Luis Gaytán de Vozmediano (1590) and Antonio Eslava's Noches de invierno (1609) contain literary motifs and small details revealing that Miguel de Cervantes had read these books. He gave them a new literary life in his own works. In this imagined memoir, they are collected side by side with Cervantes' own recreation.

Keywords: Miguel de Cervantes, literary motifs, Italian novel, Spanish fiction, reading traces, recreations. 